\title{
More Power to the Pill: The Impact of Contraceptive Freedom ON WoMen's Life CYCle LABOR SuPPly
}

by

Martha J. Bailey

Faculty Sponsor: Robert A. Margo

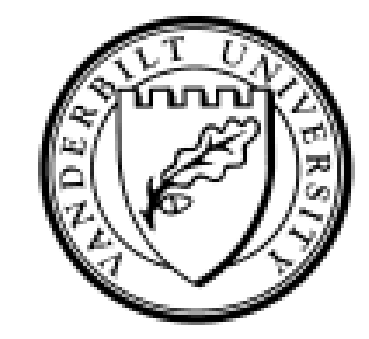

Working Paper No. 04-WG01R

May 2004

Revised July 2005

DEPARTMENT OF ECONOMICS

VANDERBILT UNIVERSITY

NASHVILLE, TN 37235

www.vanderbilt.edu/econ 


\title{
MORE POWER TO THE PILL: THE IMPACT OF CONTRACEPTIVE FREEDOM ON WOMEN'S LIFE CYCLE LABOR SUPPLY*
}

July 2005

Martha J. Bailey

\begin{abstract}
:
The release of Enovid in 1960, the first birth control pill, afforded U.S. women unprecedented freedom to plan childbearing and their careers. This paper uses plausibly exogenous variation in state consent laws to evaluate the causal impact of the pill on the timing of first births and extent and intensity of women's labor-force participation. The results suggest that legal access to the pill before age 21 significantly reduced the likelihood of a first birth before age 22, increased the number of women in the paid labor-force, and raised the number of annual hours worked.
\end{abstract}

Contact information:

University of Michigan, Department of Economics, 611 Tappan Street, 307 Lorch Hall, Ann Arbor, MI 481091220. Phone: 734-647-6874. Fax: 734-764-2769. baileymj@umich.edu

JEL: J13, J22, N32

* Research on this project was generously supported by the Vanderbilt University Summer Research Awards Program in Arts and Science and the NBER. I am grateful to Jeremy Atack, Kathryn Anderson, Dale Ballou, William J. Collins, Andrew Daughety, T. Aldrich Finegan, Claudia Goldin, Melanie Guldi, Theodore Joyce, Derek Laing, Robert A. Margo, Walter Oi, Jennifer Reinganum, John Siegfried, Gary Solon, and workshop participants at Vanderbilt and Harvard Universities and the NBER Summer Institute. I also thank three anonymous referees and the editors for helpful comments and suggestions. Dan Taylor provided outstanding research assistance. 


\section{Introduction}

The movement she [Margaret Sanger] started will grow to be, a hundred years from now, the most influential of all time. When the history of our civilization is written, it will be a biological history, and Margaret Sanger will be its heroine. ${ }^{1}$

--H.G. Wells, 1931

The release of Enovid in 1960, the first birth control pill, afforded U.S. women unprecedented freedom to plan childbearing and their careers. For college women, Goldin and Katz [2002] find that access to oral contraception led to a later age at first marriage and greater representation in non-traditional, professional occupations. But "the pill” may have had durable and far-reaching effects on women’s labor market work across levels of attainment.

Relatively little work in economics, either theoretical or empirical, has explicitly examined the impact of oral contraception on women's paid work. Indeed, this line of research may seem relatively unimportant given the compendium of historical, cross-country, and scholarly research that suggests that birth control mattered very little [cf. Becker 1991, ch. 4]. Well before the advent of the pill, the U.S. witnessed steady increases in women's laborforce participation and dramatic swings in fertility. In light of this fact, Becker's conclusion summarizes a view held by many scholars: “the 'contraceptive revolution' ... ushered in by the pill has probably not been a major cause of the sharp drop in fertility in recent decades” [1991, p. 143]. But even if the pill did reduce fertility, recent quasi-experimental research suggests that declining numbers of children can explain remarkably little of the longerterm changes in women's market work [Bronars and Grogger 1994; Jacobsen, Pearce, and Rosenbloom 1999; Hotz, McElroy and Sanders 1997; Angrist and Evans 1998]. ${ }^{2}$

The relative scarcity of empirical evidence on the impact of oral contraception relates to the difficulty of the empirical problem. The pill's introduction in 1960 and subsequent diffusion corresponded to the resurgence of the women's movement, the spread of labor-saving household technologies, the enactment and increasing enforcement of anti-discrimination legislation, and the social unrest associated with the Civil Rights Movement and Vietnam. Moreover, abortion became increasingly available around the time many young women gained access to the pill and may have had comparable effects on their fertility and labor market decisions. Similar to the strategy used by

\footnotetext{
${ }^{1}$ Margaret Sanger (1879-1966) is known as the founder of the twentieth century's birth control movement.

2 Angrist and Evans [1998, p. 474] conclude that since 1950, "the increase in female labor-force participation has been so large that declining fertility can explain only a small fraction of the overall change.” Between 1970 and 1990, the same authors suggest that the decline in
} 
Goldin and Katz [2002], I exploit a source of plausibly exogenous variation to isolate the pill’s impact on women’s lifecycle labor-force participation. This variation arises from broad, state-level changes from 1960 to 1976 that expanded the legal rights of individuals ages 18 to 21 . The indirect effect of these legal revisions, however, was to empower unmarried women under the age of 21 to consent to medical care and, by extension, obtain oral contraception without parental consent.

These laws facilitate two types of analysis of the pill's impact. First, they shaped the diffusion of the pill to younger women from 1960 to 1976 and provide a rough timeframe over which to look for relevant changes in behavior. Figure I displays trends in first birth rates by age category since 1940. Although first births among younger women increased during the Baby Boom, a marked decline in early childbearing began when the pill was introduced and lasted until 1976, when all unmarried minors in the U.S. could obtain contraceptives under the law. Notably the largest absolute declines occurred during this period among 18 to 19 year olds, the group of women most likely to benefit from liberalized access laws. In contrast, first birth rates among 15 to 17 year olds, individuals who were generally too young to benefit, underwent almost no discernible changes.

Changes in the distribution of the age at first birth also correspond closely to the diffusion of the pill. Figure II plots the fraction of women first giving birth in three-year age bins by cohort. For example, the point above age 18 denotes the fraction of women with a first birth within the age bin of 17 to 19 . Among women born before 1940 who were too old to benefit from early access, approximately 62 percent of those ever having children report a first birth by age 22. For women born around 1955—almost all of whom had access to the pill under the law — the fraction giving birth by age 22 had declined by 16 percentage points, or roughly 25 percent. ${ }^{3}$ Stark differences between cohorts with (1955 to 1960) and without (1933 to 1940) early access to the pill suggest that these changes are not due to pre-existing trends. Moreover, there appear to be almost no visible changes in the distributions after 1955, when all young women would have had early access. ${ }^{4}$

A rapid transformation in women's lifecycle labor-force participation profiles occurred between the cohorts of

childbearing beyond the second child among women ages 21 to 35 can account for roughly two percentage points (of the total 16.8 increase) in employment.

${ }^{3}$ The cohort of 1955 is relevant because the U.S. Supreme Court decision, Planned Parenthood of Central Missouri v. Danforth, in 1976 ruled against a state's compelling interest to regulate access to contraception based on age alone.

${ }^{4}$ The oldest women observed in the 1955 to 1960 birth cohorts were ages 40 and 35 respectively in the 1995 June CPS, the last survey to ask about the year the first child was born. To the extent that women in these cohorts delayed their first births beyond ages 35 and 40 , the fraction of women born between 1955 and 1960 giving birth at earlier ages should be overstated and those delaying understated. Therefore, the 
1940 and 1955 as well. As shown in Figure III, women born during the first forty years of the century tended to withdraw from the labor-force during the ages of high fertility. As more women returned to work after their children had grown, increases in the market participation of women over 30, especially married women, drove increases in aggregate participation rates (cf. Goldin [1990]) until the 1960s. This pattern reverses with cohorts born after 1940. For those born in 1955, the “fertility dip” in labor-force participation had completely disappeared. Participation rates were 24 percentage points higher at age 25, and 20 percentage points higher at age 30, than those of women born in $1940 .^{5}$ This rapid, inter-cohort shift in young women's labor market participation during the twentieth century occurred over the same period as younger and unmarried women gained legal access to oral contraceptives.

While cross-cohort trends are suggestive, the remainder of this paper examines average within cohort effects of early access using implied legal variation by year of birth and state for women born from 1940 to 1955 . The estimates suggest that access to the pill before age 21 reduced the likelihood of becoming a mother before age 22 by 14 to 18 percent and increased the extent of 26 to 30 year old women's labor-force participation by approximately 8 percent. At the intensive margin, women with early access worked at least 68 more annual hours at ages 26 to 30. These findings do not challenge the validity of past research on the relationship between the number of children and women's labor supply. Rather, they are consistent with the notion that the pill catalyzed changes in labor-force participation through the mechanism of birth timing. By providing a low cost means of delaying childbearing, oral contraception allowed women to remain in school, pursue longer-term careers, and work more in the paid labor-force during ages historically associated with childrearing.

\section{The theoretical impact of early access to the pill on women's lifecycle labor supply}

While a number of relatively effective contraceptive methods were available well before the introduction of Enovid in 1960, oral contraception revolutionized the technology of birth control in three important ways. ${ }^{6}$ First, the pill constituted the first female contraceptive. A woman could independently decide to take the pill; it did not

\footnotetext{
inability to observe younger cohorts at older ages tends to make the shift between 1940 and 1955 appear smaller than it is.

${ }^{5}$ Smith and Ward [1985, p. S65] also note that for women born after 1950, there is no observable employment decline over the childbearing years. Goldin [2002, Figures 4 and 5] notes that these trends are borne out for married women as well, although the labor market integration of college graduate women appears to have begun earlier.

${ }^{6}$ The withdrawal method, or coitus interruptus, had been used well before it was popularized in the U.S. in Robert Dale Owen's 1831 pamphlet, Moral Physiology. A number of other contraceptive methods, such as the condom and diaphragm, had also been adopted before the pill was available [Brodie 1994]. For a thorough history of the condom, see Brandt [1985] and Valdiserri [1988].
} 
require the consent or knowledge of men or discomfort to either party during sex. The pill transferred control of contraception, which had long resided with men, to women who bore the high physical and opportunity costs of childbearing. Second, the pill divorced the decision to use contraception from the time of intercourse. This lowered the marginal costs of preventing births during sex to zero and shifted decisions about contraception to times separate from the act of intimacy. Third, the pill's effectiveness far exceeded that of all other methods available in 1960. ${ }^{7}$ Whereas most couples regarded pregnancy risk as part of the cost of intercourse, oral contraception virtually eliminated concerns about unwanted conception [Michael and Willis 1972, Willis 1973, Marks 2001]. By reducing the costs of preventing and timing childbirth, improvements in the technology of birth control may have mitigated the constraints imposed by fecundity on women's labor-force participation. As a result, more women may have entered and remained in the paid workforce.

One might infer from recent studies that the potential effect of the pill on women's fertility and labor-force participation is small. Using biological events to identify the impact of an additional child on women's labor supply, the bulk of compelling research finds only a modest effect (twinning [Bronars and Grogger 1994; Jacobsen, Pearce, and Rosenbloom 1999] or miscarriages [Hotz, McElroy and Sanders 1997], or the sex of children already born [Angrist and Evans 1998]). Using variation in the number of births may understate the pill's impact for two reasons. First, only women who chose to become pregnant (or for whom prevention was too costly) enter the sample. The impact of an unexpected birth may be considerably smaller for these women than for those who are childless or are not expecting a child. Second, these studies abstract from the pill's potential effect on labor supply through birth timing. ${ }^{8}$ Because couples were fairly accurate at reaching their target fertility before the pill, fairly costless birth timing technology may be among its most important contributions. ${ }^{9}$

The empirical exercise in this paper allows one to assess the importance of the pill through birth timing using

\footnotetext{
${ }^{7}$ From the beginning, Enovid's advocates promoted the pill as 99 percent effective. Although numbers on the effectiveness of contraception are dubious at best, Planned Parenthood estimates the failure rates associated with typical use of the condoms available today at around 15 percent and the failure rates of today's modern diaphragms at around 16 percent. It is unclear how much of this figure is attributable to inappropriate use. Less effective spermicides and materials imply that failure rates of these methods would have been much higher in 1960. ${ }^{8}$ Klepinger et al. [1999] provide an excellent review of studies that relate early childbearing to women's outcomes including education, experience, labor-force participation and wages. Most find that early childbearing has a negative effect on each of these outcomes. Miller [2005] and Vere [2004] also examine the impact of birth timing.

${ }^{9}$ The pill revolutionized a couple's ability to time childbearing. Primitive methods of birth control included delay of first marriage, longer breast-feeding to delay the return of menses, withdrawal and the reduced frequency of coitus. Modern alternatives were condoms and diaphragms. Couples anticipated periodic failure of any of these methods and most employed a variety of methods to hit their target fertility. Before the pill, no method—save abstinence—-facilitated the deliberate timing of childbearing.
} 
“early access to the pill”, defined as unrestricted legal access for unmarried, childless women between ages 18 and 20. This focus may seem narrow, but decisions at ages 18 to 20 strongly influence young women's career path. Not only do women make choices about human capital investment and occupation, but among women reaching that age before the pill was released, roughly 50 percent had married and more than 40 percent had conceived by their $21^{\text {st }}$ birthdays. ${ }^{10}$ During these ages, the risk of pregnancy (for married and unmarried women) not only threatened to disrupt human capital investments in the immediate term [Goldin and Katz 2002] but may have reduced their initial career investments as they expected unplanned, future spells out of the labor-market.

Early access to the pill potentially affected women’s lifecycle labor supply by reducing the costs and increasing the returns to pursuing careers. ${ }^{11}$ First, early access reduced the cost of delaying pregnancy in order to make career investments. Young women could stay in the labor market, invest in careers (through formal schooling or training or on-the-job experience) and be sexually active (or marry) without the risk of pregnancy. Second, early access increased the expected lifetime returns to career investments by making the timing and number of spells out of the market a deterministic process. ${ }^{12}$ Finally, early access may have increased labor supply even among women with no career aspirations per se. For instance, women may have worked more to help their husbands gain more education or reach a certain career stage so as to increase lifetime consumption [Happel et al. 1984].

While past empirical studies have emphasized the impact of changes in the number of children on labor supply, the argument here is that early access to the pill may have affected women’s work behavior without affecting completed fertility. In fact, variation in early access may produce weak, if any, effects on the number of children ever born. After the pill was introduced in 1960, almost all women born later than 1940 obtained access to the pill at age 21, by legal emancipation by marriage, or first birth. An ill-timed, early pregnancy could be offset by using contraception to reduce births at ages beyond 21 . Thus, women with early access should be equally likely to achieve their target number of children. ${ }^{13}$

\footnotetext{
${ }^{10}$ These figures are based on the author's computations using a sample of women who had married at least once by age 35 and who were born from 1935 to 1940 in the June CPS.

${ }^{11}$ The intuition laid out here is consistent with the theoretical models in which rational agents make choices at the outset of their adult lives, given their preferences and abilities, which effectively determine the sequence of childbearing, labor-force participation, and wage outcomes. See Hotz, Klerman, and Willis [1997].

${ }^{12}$ Weiss [1986] outlines why expected career interruptions reduce pre-interruption career investments. Mincer and Polachek [1974] cite the expectation of career interruptions as one reason, even after accounting for past interruptions, earnings differ between men and women.

13 The exception to this statement is for women who desired no children. A more difficult question is whether early access (not the pill itself) alters the target number of children. Becker argues that birth control should not affect the demand for children [1991, p. 143], for which an
} 


\section{Identifying the effect of early access to the pill using variation in state laws}

The nature of the birth control pill as a prescription pharmaceutical renders variation in legal access a convenient tool for studying its impact. While it is questionable whether restrictive state laws were enforced for other forms of contraception, obtaining the pill required a prescription from a licensed physician and sale by a licensed pharmacist. ${ }^{14}$ Violations of state laws could be punished with heavy fines, jail time, and possibly the loss of one’s professional license [Garrow 1994]. For this reason, restrictions that required a young woman to be a legal adult (over the age of 20 in most states); married, pregnant or a mother (most states granted "legal emancipation” under any of these conditions); or the legal consent of a guardian imposed binding constraints on young women's decision to obtain the pill. ${ }^{15}$

\section{III.A. The history of liberalization of access to oral contraception for younger women}

During the 1960s and 1970s, the age of legal consent was lowered at different times in different states for reasons largely unrelated to issues surrounding contraception or women’s rights. Most of these legal changes, in fact, were due either to the expanding rights of legal minors or to changes in the definition of legal "minority".

The trend toward the legal empowerment of minors began well before the introduction of the pill. In 1956, an early Ohio case in 1956 recognized a "mature minor” doctrine, waiving the requirement of parental consent for medical care if the minor was "intelligent and mature enough to understand the nature and consequences of the treatment” [Paul, Pilpel, and Wechsler 1976, p. 16]. After the pill was introduced, many of these decisions gave physicians latitude to prescribe oral contraception to young women without consulting their parents [Paul, Pilpel, and Wechsler 1974].

As judicial precedents extended the legal rights of minors, the war in Vietnam catalyzed changes in the definition of legal adulthood, or age of legal “majority”. Under federal law, one could be drafted for Vietnam at age 18 but could not vote until age 21. This discrepancy in rights and obligations of young men reached national

empirical proxy is completed fertility. This is also consistent with theoretical models of lifecycle fertility, which unambiguously predict that wealth-constant changes in the prices of preventing childbirth or working in any given period will affect the lifecycle timing of births but not necessarily completed fertility [cf. Hotz, Klerman and Willis 1997, p. 309-317].

${ }^{14}$ Effective regulation of condoms, for instance, required only that distributors (often gas station clerks) check the age and/or marital status of those making purchases. A substantial amount of evidence suggests that the illicit distribution of non-hazardous contraceptives over the counter or in vending machines was common before they were legal [cf. Garrow 1994, p. 188].

${ }^{15}$ One final feature of legislative history makes state legal changes a particularly apt quasi-experiment. The Comstock Act, which was passed by Congress in 1873, declared the inter-state transport or mailing of contraceptives a federal offense. Although the One Package U.S. Supreme Court ruling struck down federal bans on the inter-state shipping of contraception to licensed physicians in 1936, federal law continued to prohibit individuals from obtaining oral contraceptives by mail from out-of-state. Individuals seeking to obtain the pill would 
prominence during the 1968 national presidential election. After coming to office, Nixon's support of lowering the federal voting age to 18 culminated in the ratification of the Twenty-Sixth Amendment to the U.S. Constitution in 1971. At the state level, legislatures began extending the privileges and responsibilities of legal adulthood to eighteen-year old men and women as well. ${ }^{16}$ Although extending the right to obtain contraception to younger women had little, if anything, to do with these legislative changes, a lower age of majority empowered them to consent to medical treatment and, by extension, obtain the pill. ${ }^{17}$ (In the subsequent discussion, I will refer to these states as "age of majority" states).

During the same period, equally visible and controversial issues were decided in the U.S. Supreme Court. Beginning with the Griswold decision in 1965, the Court struck down Connecticut's ban on the use and distribution of contraceptives and declared a realm of "procreative privacy" for married individuals. In subsequent rulings, the right to privacy was held to apply to unmarried individuals in Eisenstadt v. Baird and finally, in 1976, to minors. In 1976 Planned Parenthood of Central Missouri v. Danforth, the Supreme Court ruled that states lacked a “compelling interest” in using age as the sole criterion under which to regulate contraceptive access. This decision, by no act of popular opinion, rendered the higher age of legal majority inapplicable to the prescription of oral contraception.

I have collected the earliest state laws which empowered unmarried women under the age of 21 to obtain the pill without parental consent. ${ }^{18}$ Table I lists the date and source of legal change for each of the fifty states and the District of Columbia. To the extent that these legal changes do not capture women's ability to pay or physician's willingness to prescribe the pill, they are only proxies for early access in practice.

III.B. The validity and relevance of liberalization as a natural experiment

In order to use these laws to make inferences about the pill's causal effect, the timing of liberalization should

have had to drive across state lines regularly to refill prescriptions and for checkups.

${ }^{16}$ Several states regarded 18 year old women as legal adults much earlier than the 1970s, while retaining 21 as the age of majority for men. I take these laws to apply to medical consent and obtaining contraceptives.

${ }^{17}$ These rights generally included signing contracts; suing and being sued; making wills; inheriting property; holding public office; serving as jurors, policemen and firemen; marrying and divorcing without parental consent; qualifying for welfare benefits; and attending X-rated movies. In many states, court cases challenged specific provisions of the lower age of majority, but none that I am aware of challenged a young woman's right to consent to medical care.

${ }^{18}$ Liberalization often occurred through the interaction of different legal changes. For instance, liberalization did not occur in Ohio until the U.S. Supreme Court decided Griswold which, in practice, struck down Connecticut's Comstock law. However, because Connecticut's statute was more restrictive than Ohio's restrictions on contraception, Griswold enjoined Ohio's statute as well. In conjunction with Ohio's mature minor doctrine of 1956, therefore, Griswold effectively granted early legal access to contraception. 
not reflect pre-existing differences in state-level characteristics. The legal history of the liberalization of access suggests little connection to state-level characteristics relating to women’s fertility and employment choices. ${ }^{19}$ Nevertheless, I evaluate this assumption empirically by generating state-level characteristics for each of the fifty U.S. states and the District of Columbia from the 1960 Public Use Microsample [Ruggles and Sobek 2004], the Survey of Churches and Church Membership [National Council of Churches of Christ 1956], and the record of Casualties in Southeast Asia [National Archives 1997]. For each state, I construct a dependent variable, “time to liberalization”, as the number of years that elapsed from 1960, the year the pill was released, until unmarried women under the age of 21 could obtain oral contraception without parental consent in the particular state.

Table II reports point-estimates and robust standard errors from cross-state regressions of "time to liberalization” on selected 1960 state characteristics. The panels group the correlations into four broad categories. Panel A includes the demographic characteristics such as the fraction of the state's population who work in agriculture, were foreign born, black or in different age groups. Panel B includes proxies for education, state fertility norms such as the mean age at first marriage and completed fertility of the older generation, poverty rates, fraction Catholic, and the number of Vietnam casualties from 1965 to 1970 as a fraction of the state population. ${ }^{20}$ Panel C reports the results of regressions on proxies for household technology such as washers, dryers, and freezers as well as the fraction of households with two or more cars. Panel D includes labor market characteristics for men and women such as the labor-force participation, unemployment, and mean wages among 22 to 30 year olds.

The striking feature of Table II is that none of the characteristics is statistically significant, with the exception of the fraction Catholic. A larger fraction of Catholic parish membership in 1952 is associated with a statistically significant delay in liberalization. According to the political history described in Garrow [1994], this relationship might be driven by a strong Catholic lobby against statutes or judicial decisions that directly liberalized access to contraception. Because I cannot control directly for fraction Catholic in the analysis (the variable is only available for a handful of years), I include state fixed effects and linear state trends in the analysis and test the robustness of

\footnotetext{
${ }^{19}$ Three states that passed comprehensive family planning laws are the exception. By 1972 Georgia, Wyoming, and the District of Columbia passed laws that either explicitly allowed for the treatment of "every patient desiring services" or were broad enough that physicians could treat patients of any age or marital status without liability.

${ }^{20}$ The number of casualties in Vietnam is intended to proxy for state-level political pressure to change the age of majority. The date range 1965 to 1970 is chosen because the $26^{\text {th }}$ Amendment was ratified in 1971 , but the results are not sensitive to small changes in the dates.
} 
my results by running the analysis on age of majority states only. ${ }^{21}$ The lack of a statistical relationship with other potential correlates lends credibility to an empirical strategy that treats legal changes as a valid quasi-experiment. It seems fair to conclude that idiosyncratic differences in the regional judiciary and legislatures, the regional politics of minors’ rights and the war in Vietnam resulted in considerable variation in the timing of adoption across states.

Whereas the legal changes appear to be a valid natural experiment to evaluate the effects of early pill access, little direct information exists on their relevance for pill use in practice. As noted in Goldin and Katz [2002], only one known dataset in existence, the National Survey of Young Women [1971], contains information on both state of residence and contraceptive use among unmarried teenage women during the appropriate time period. With these data Goldin and Katz [2002] find that, in states with liberalized access, pill use was 36 to 40 percent greater among unmarried 17 to 19 year old women. ${ }^{22}$ To bolster further the argument that liberalized access to the pill is, indeed, generating the observed labor market effects through the mechanism of fertility control, I provide additional evidence that early access facilitated a delay in the age at first birth and that only women who delayed childbearing worked more in the paid labor market.

\section{Data and estimation results}

The June and March Supplements to the CPS consist of repeated cross-sections (not annual in the case of the June Supplements) and contain detailed information on individual characteristics including retrospective information on the age at first birth and completed fertility (June Supplements); labor market participation including hours worked in the reference week, and weeks worked in the previous calendar year (March Supplements); and information on current residence (both surveys). For the June sample, I restrict my attention to women ages 36 to 44 at the time of observation as they are most likely to have begun (and completed) their

\footnotetext{
${ }^{21}$ The history of these laws suggests that they were least likely to be influenced by Catholic, anti-contraception political interests. For states changing through age of majority, the coefficient on fraction Catholic falls to 1.77 with a robust standard error of 1.70 . Repeating the analysis presented in Table II for the age of majority states only yields one statistically significant relationship. A higher fraction of a state's population killed from 1965 to 1970 in South East Asia tended to hasten a reduction in the age of majority (correlation = -2.24, s.e.=1.23). This provides empirical support for the political history: higher casualty rates increased pressure to change the legal age of majority, but the timing of these legal changes is not predicted using other state correlates.

${ }^{22}$ Qualitative evidence also supports this claim. The journal of Family Planning Perspectives provided regular updates from 1968 to 1978 on changes in the age of majority and mature minor doctrines to inform physicians and family planning organizations of the permissiveness of often ambiguous state laws. Moreover, the Department of Health Education and Welfare commissioned a study in 1971 of differences in state laws regarding fertility control [DHEW 1974]. Sub-sections of this report on young women's access to contraception regularly begin with references to the legal age of majority in a particular state as well as the other laws. It is also clear from these reports that state welfare agencies and public health departments developed rules regarding contraceptive access based upon legal restrictions in a given state.
} 
childbearing. ${ }^{23}$ The March sample is restricted to women between ages 18 and 44 years old who were not working in the military or incarcerated. I additionally omit observations with allocated values on the dependent variable [cf. Hirsch and Schumacher 2004] and limit the analysis to women born between 1935 and 1960.

The June CPS provide an advantage over the decennial census, because in most years women were surveyed about the year in which their first child was born. The advantage of the March CPS lies in their annual collection that allows cohort behavior (defined by year of birth) to be tracked across ages. ${ }^{24}$ Several features of these data, however, may minimize the estimated effects. First, the distribution of the pill for reasons other than birth control (e.g. to prevent cramps or regulate menses), otherwise unenforced legislation, the lack of financial accessibility, and cross-state travel to obtain the pill should bias my results toward zero. Neither the CPS nor other sources provide a way to account for these possibilities or gauge the magnitude of attenuation they introduce, so the estimates should be regarded as conservative. Second, the CPS provide no information on a woman's state of birth nor the location of her residence around her twenty-first birthday. It is, therefore, necessary to assume that changes in legal access in the observed residence were relevant to the individual's decisions before age $21 .^{25}$ As time passes women are less likely to be observed in the state where they resided at age 21, and, thus, this source of measurement error may be larger for older women. ${ }^{26}$ However, a separate analysis using state of birth and state of residence in the decennial census suggests that the inability to observe state of residence around age 21 leads only to slight attenuation of the estimates. ${ }^{27}$

IV.A. The impact of early access to the pill on age at first birth

Cross-state heterogeneity in legal access by year of birth facilitates estimation of the pill’s average withincohort effect on childbearing. I estimate equations of the following general form,

\footnotetext{
${ }^{23}$ Observing women in each cohort at age 44 would be ideal, but the first birth year is observed for the 1956 and younger cohorts in two years. I have chosen age 36 as a cutoff to retain a reasonable number of observations on year of first birth from these younger cohorts.

${ }^{24}$ The decennial census only asks about children currently in the household, so the age at first birth cannot be computed for women with children living out of the household. For the labor-force estimates, decennial census provides snapshots only every ten years of labor-force participation for women born in a given year and, therefore, less information on age-specific labor-force participation by cohort.

${ }^{25}$ For example, a 35-year-old woman observed in Massachusetts in 1985 would have been 24 when the Massachusetts liberalized access. Therefore, I code her as without early access, although I do not know where she was living before her $21^{\text {st }}$ birthday.

${ }^{26}$ Specifically, the estimated long-term effects of early access are based upon the sample of non-movers. If non-movers are women who do not take advantage of labor market opportunities in other states, the long-term effects of early access will also be underestimated.

${ }^{27}$ Estimates obtained from the 1960 to 1990 Integrated Public Use Micro Samples suggest that measurement error is random and not due to, for instance, differential migration of career-minded women to states where they would have had early legal access, or $E L A$ [Ruggles and Sobek 2004]. Using specifications comparable to those in Table IV and V, I generate two measures of ELA: one based on state of residence and one based on state of birth. While neither measure provides perfect information on state of residence around age 21 , birth state may be a better proxy for the legal environment at that age. Moreover, birth state is not subject to migration bias induced by career decisions.
} 


$$
Y_{i c s}=\alpha_{0}+\alpha_{1} E L A_{i c s}+f_{s}+g_{c}+\varepsilon_{i c s},
$$

where $Y$ denotes a fertility outcome, $f_{s}$ and $g_{c}$ denote a set of state and individual year of birth dummy variables. State linear time trends $\left(f_{s} \cdot c\right)$, included in some specifications, capture gradually evolving, unobserved state characteristics. Early legal access to the pill, $E L A$, is equal to one if women born in year $c$ would have had access to oral contraception before age 21 in their current state of residence, $s . E L A$ varies by year of birth, $c$, and state of residence, $s$, for women born from 1940 to 1956, but I also include cohorts born from 1935 to 1960 in order to control for pre-existing trends.

Table III reports the marginal effects of early access on various measures of fertility. Probit specifications are used for the binary dependent variables in the first five columns and the standard errors are corrected for clustering on state of residence and year of birth cells. Columns 1 through 3 present the estimates for the dependent variable equal to one for women giving birth before age 22 (or conceived by age 21) and zero for those having children at 22 or later. The baseline estimate in column 1 (without state trends) implies that early access to the pill reduced the likelihood of a birth before age 22 by roughly 14 percent $(-0.071 / 0.497) .{ }^{28}$

But is the effect causal? Identification of $\alpha_{l}$ in this framework comes from the interaction between year of birth and state of residence. With the inclusion of state and cohort fixed effects, identification is threatened if unobservable factors vary across states and within birth cohorts or within states and across birth cohorts with the proximate pattern of ELA. Moreover, in contrast to studies which use cross-state variation in the enactment of laws at the same level or branch of government which target a specific policy outcome, the laws used in this analysis were enacted at different levels of government and targeted different policy outcomes. Only indirectly did most of these laws extend access to oral contraception. Precisely this heterogeneity makes it difficult to come up with an alternative omitted variable, correlated with the timing of liberalization, which is not related to ELA.

Nevertheless, it is instructive to consider several potential threats to the validity of a causal interpretation. For instance, gradual changes in the fraction Catholic, the growth in the women's movement, or other unobserved trends may have tipped legislators in favor of liberalization and induced women to delay childbearing independently of ELA. Controlling for these forces directly is not possible in a state-cohort panel. However, the

${ }^{28}$ The inclusion of women without children (zeros for the binary variable for first birth before 22) implies a 16 percent decline in the 
inclusion of state-specific linear time trends should capture unobserved factors within states that evolve smoothly across cohorts. Adding state trends in column 2, however, changes the results negligibly.

Another concern is that the effect of greater early access to abortion from 1970 to 1973 may be confounded with the effect of the pill among the younger cohorts. Directly controlling for early access to abortion in column 3, however, actually strengthens the magnitude and statistical significance of $E L A$ to the pill among cohorts in states without early access to abortion $(-0.093$, s.e. $=0.043)$. In this specification, those with early legal access to abortion are 14 percent less likely (-0.074 / 0.497) to give birth before age 22, although the estimate is not statistically significant. As captured in the interaction of early legal access to the pill and abortion, the effects are not appreciably different in states with both types of fertility control. This does not imply that abortion was unimportant, but early access to abortion does not appear to drive the results reported here. ${ }^{29}$

Yet another concern is that the development of a strong women's movement or the diffusion of labor saving technologies in the household may be related to both legal changes and women's desire to have children and work. One way to test this hypothesis is to examine the correlation of these laws with proxies of a cohort's attitudes about motherhood and childrearing as revealed in their behavior. For instance, because the laws considered in the analysis generally lowered the age of pill access to 18, first births by age 18 (conceptions at 17) should not be affected. Finding an effect of $E L A$ on a group that should not have benefited from liberalization would suggest that $E L A$ is picking up changes in other unobservables rather than earlier pill access. The very small and statistically insignificant estimate in column 4 bolsters the case that $E L A$ did not affect women who were not generally “treated” with liberalization.

Another way to examine the effect of ELA on women's attitudes about motherhood uses measures of completed fertility. Women with and without ELA should be equally likely to achieve their target fertility levels, because, as noted previously, virtually every woman after 1960 obtained access to contraception at marriage, at age 21 or after bearing one child. ${ }^{30}$ An ill-timed or unwanted birth among those without early access could be easily

likelihood of a first birth before age 22.

${ }^{29}$ For results on the importance of abortion for general fertility rates (not first birth rates) see Levine et al [1999] or for labor-force outcomes see Angrist and Evans [1999]. Guldi [2004] provided careful research on legal access to abortion for unmarried women under the age of 21. Early access to abortion is coded as 1970 for Alaska, California, Hawaii, New York and Washington. 1972 is coded for Vermont and New Jersey. All other states permitted early legal access with Roe v. Wade in 1973.

${ }^{30}$ See, for instance, Becker [1991, p. 143] who argues that fertility control should have little effect on the demand for children. 
offset by reducing subsequent births with the pill. Therefore, a strong effect of $E L A$ on completed fertility would suggest that $E L A$ altered target fertility levels or that ELA is really capturing underlying changes in women's attitudes about motherhood and career. The data reject this hypothesis. By age 36, the marginal effect of $E L A$ on the likelihood of bearing a child by age 36 among those ever having children falls very close to zero as presented in column $5 .{ }^{31}$ Column 6 presents estimates of $E L A$ on the number of children at the same age. In states without early access to abortion, the ELA appears unrelated to the number of children ever born by age $36 .^{32}$

Finally, because $E L A$ varies only for 18 to 20 year olds, one might argue that an effect should appear only for women in that age group. That is, ELA should have no effect on the likelihood of first birth by age 24 (conception at age 23). But if relaxing the constraints on young women's choices allowed them to select into different career trajectories, ELA may affect optimal birth timing well beyond age 21. The magnitude of this effect should erode, however, as more women select into motherhood. Consistent with this prediction, the effect of $E L A$ on first births before age 23 is smaller, but still large and statistically significant $(-0.086$, s.e. $=0.044)$. The effect on first births before age 25, however, is relatively and absolutely smaller in magnitude and no longer statistically significant (0.049 , s.e. $=0.039)$. The effect on first births by age 27 is even smaller in magnitude and far from statistically significant $(-0.021$, s.e. $=0.034)$. Therefore, the labor market effects reported later in the paper should be viewed as arising from improvements in the timing of motherhood rather than through reductions in the number of children.

\section{IV.B. The effect of early access on lifecycle labor supply}

The employment data in the March CPS provide annual work information from 1964 to 2001 and allow withincohort, age-specific labor-force participation effects to be separated from the secular growth in women's market work. One shortcoming of the March data is that smaller states are grouped with others from 1968 to 1976 . For this reason, the labor-force analysis examines 21 CPS regions (some individual states or D.C.) in order to capture consistent geographic units over the entire period. With this limitation, I redefine $E L A$ in $C P S$ region $r$ in year $t$ for a woman $j$ years beyond her twentieth birthday as

$$
E L A_{r, t-j}=\left[P_{r, t-j}\right]^{-1} \sum_{s \in r} P_{s, t-j} \times 1\left(\operatorname{Law}_{s, t-j}\right)
$$

\footnotetext{
${ }^{31}$ In results not reported here, I find that $E L A$ also does not have a discernible effect on selection into childlessness.

${ }^{32}$ ELA does not appear influence selection into motherhood either. Without controls for abortion, the point estimate in column 4 becomes 0.007 (s.e. $=0.018$ ) and in column 5 becomes 0.009 (s.e. $=0.027$ ). The point estimate in column 6 becomes -0.119 (s.e. $=0.072$ ). However, all of
} 
where $P_{r, t-j}$ denotes the population of region $r$ in year $t-j$ and $P_{\mathrm{s}, t-j}$ denotes the population of state $s$ in region $r$ in the year $t-j$, the date of the woman's twentieth birthday; and $1(\mathrm{)})$ is an indicator function equal to one if state $s$ had a liberal access law in year $t-j .{ }^{33}$ Thus, this variable can be interpreted as the probability that a woman currently residing in region $r$ in year $t$ would have had access to contraception before her twenty-first birthday, assuming that she had not moved. This probabilistic approach introduces yet more error into the measurement of $E L A .^{34}$

The base specification allows ELA to alter the shape of women's labor-force participation profiles through its interaction with a set of categorical age dummies denoted by vector $\boldsymbol{A} .^{35}$ I estimate equations of the general form,

$$
Y_{i c a r}=\beta_{0}+\boldsymbol{A}_{i c a r} \beta_{1}+E L A_{c r} \times \boldsymbol{A}_{\text {icar }} \beta_{2}+f_{r}+g_{c}+h_{c+a}+\varepsilon_{\text {icar }},
$$

where $c$ refers to the year of birth, $r$ to the CPS region, and $a$ to the age of the cohort of observed. The fixed-effects $f_{r}, g_{c}$ and $h_{c^{+} a}$ denote dummies for CPS region, year of birth (cohort), and year of observation respectively. I include region-specific linear time trends $\left(f_{r} \cdot c\right)$ in some specifications to capture gradually evolving, unobserved state characteristics that may have changed labor-force outcomes independently of the pill. In this specification, each element of $\beta_{2}$ captures the average, age-group specific, within-cohort, within-state impact of early legal access to the pill.

Table IV reports estimates of the marginal effects of ELA on the extent of labor-force participation. A probit specification is used for the binary dependent variable for labor-force participation, i.e. worked or looked for work for most of the week prior to the survey. The estimates in columns 1 and 2 (the base-line specification with and without region-specific linear time trends, respectively) are quite similar. With early legal access, the participation rates of women ages 26 to 30 were around four percentage points higher (an increase of seven percent) and approximately two percentage points higher at ages 31 to 35 at the mean. However, there are no discernible effects for women ages 21 to 25 or among women over age 35. Columns 3 and 4 examine the robustness of these results within the sample of age of majority states and the inclusion of measures of early abortion access. ${ }^{36}$ The estimates

the negative effect appears in states which also provided early access to abortion (column 6, Table III).

${ }^{33} E L A$ varies by birth year and CPS region, since $t$ and $j$ uniquely define a birth cohort. Year of birth is $t-j-20$.

${ }^{34}$ I examine aggregation error by limiting the analysis to the years 1977-2001, a period over which the CPS individually identifies all the states. Controlling for individual state fixed effects rather than CPS region fixed effects does not substantially alter the estimates.

${ }^{35}$ The elements of $\boldsymbol{A}$ are five dummy variables equal to one if a woman falls in the particular age category. The categories are 21 to 25 , 26 to 30, 31 to 35, 36 to 40, and 41 to 45 . The category 16 to 20 is omitted.

${ }^{36}$ Early access to abortion is defined using the same methodology as ELA. The regressions with abortion control include the measure of abortion described in footnote 29 interacted with $\boldsymbol{A}$. 
presented in column 4 can be interpreted as the marginal effects of early access to the pill for cohorts reaching the age of 21 for cohorts without early legal access to abortion. In both cases, the results remain within a 95 percent confidence interval of the baseline specification. ${ }^{37}$

The paper's evidence, thus far, suggests that the mechanism responsible for changes in women's labor-force participation is the delay in childbearing. If this is correct, then women with ELA who did not delay childbearing should not be observed working more. Said another way, if the labor market participation rates of these women are greater than women without $E L A$, one would suspect that the estimated effects reflect unobserved factors rather than the treatment effects of early access. Column 5 of Table IV uses the limited labor-force information in the June CPS to test this. The absence of an effect among women who gave birth before age 22 across ages provides strong evidence for the delay of childbearing as the mechanism linking increased labor-force participation to the pill.

The lack of an effect at ages 21 to 25 is consistent with Goldin and Katz [2002], who argue that ELA facilitated greater human capital investment, as well as with the literature linking teenage childbearing to reductions in human capital acquisition through labor-force participation [cf. Klepinger, Lundberg, and Plotnick 1999]. If younger women with early access spent more time in school, then they may not work more. This is supported using a CPS question about what the respondent was doing “most of last week”. From 1964 to 1988, an individual not in the labor-force could respond that the reason for not working for pay was that she was "in school”. For women ages 16 to 30, I estimate a probit model using the baseline specification in Table IV with a binary dependent variable equal to 1 if a woman reported being "in school” rather than being in the paid labor-force. I replace the five-year age dummies with six, two-year age dummies and their interaction with $E L A$ for women ages 18 to 20, 21 to 22, and so forth. ELA is associated with 0.043 (s.e. 0.008 ) percentage point increase in enrollment among women 18 to 20 , 0.047 percentage point increase at ages 21 to 22 (s.e. 0.008 ), and 0.023 percentage point increase at ages 23 to 24 (s.e. 0.005). There appears to be no effect on enrollment over age 24.

The lack of a difference in labor-force participation between women with and without ELA at older ages is more difficult to assess using the CPS. First, women who bore their children during their twenties may be returning

\footnotetext{
${ }^{37}$ I also investigate the effect of Vietnam on women's outcomes independent of changes in the age of majority. If coming of age during Vietnam held different reasons for women to defer marriage, childbearing or to invest more in formal market work, then changes in the age of majority related to mobilization may be related to women's decisions for reasons other than pill access. On the other hand, draft deferments for being a father or married may have worked to promote earlier marriage or childbearing. After allowing for an age-specific
} 
to the labor market during their later thirties. Thus, the econometrician would observe a falling difference in labor force outcomes between the two groups as more women without ELA reenter the labor-force. Second, as women age, they are less likely to reside in the same state as at age 21 , so measurement error due to migration may obscure the effect as women age.

Changes in the intensity of labor supply underscore the possibility of changing career investment in the form of market work as well. Table V presents the regression results for three dependent variables: hours worked, weeks worked and the product of the two that provides a proxy for annual hours worked. ${ }^{38}$ Across the three dependent variables, the pattern of results is quite similar to those at the extensive margin. The impact on the three measures is largest at ages 26 to 30, when women with early legal access appear to be working 68 to 107 more annual hours (or 1.7 to 2.7 more full-time weeks per year). This suggests that cohorts with early legal access acquired at least 650 more hours of work experience per person by age 35 than their peers without early access ${ }^{39} E L A$ appears to have no effect on work intensity at ages under 24 or above 36 . Because these estimates are conditional upon being in the workforce, selection makes them difficult to interpret. On the one hand, negative selection into the labor-force at the extensive margin would tend to bias the estimates for hours and weeks worked downwards for younger women (as the most productive and educated women were already working). On the other hand, early access may have affected selection in a less straightforward manner, as women reorganized the traditional sequence of childbearing and work to suit the pursuit of both family and career. While the CPS data do not allow me to weigh the relative importance of these possibilities, more research on the changing age structure of women's employment and childbearing and its relationship to contraception is certainly warranted.

IV.C. The effect of early access through career choice and human capital accumulation

Labor market participation effects at the extensive and intensive margins are consistent with the notion that ELA to the pill changed women's lifetime career paths. Economic theory suggests that these effects may arise from greater human capital investments and changing career choices [Goldin and Katz 2002]. Using the limited

effect of the number of casualties in Vietnam as a fraction of the region's population in a given year (this variable is nonzero from 1965 to 1976), the effect of early access for 26 to 30 year olds and 31 to 35 year olds is quite comparable to the marginal effects presented.

${ }^{38}$ As the March CPS reports intervals for weeks worked before 1976, I use the interval means suggested by Unicon in the estimation.

${ }^{39}$ Cohorts of women that would have been in the labor force without ELA should have gained 68.5 additional annual hours for five years during their late twenties and 50.3 during their early thirties for a total of 594 hours. In addition, the number of women working in cohorts with $E L A$ was larger because labor-force participation increased at the extensive margin as well adding another 58 hours. 
information on occupation in the $C P S$, I generate eight, crude but comparable career dummies as well as a set of dummy variables for highest grade attended in school before 1992. The inclusion of only occupation dummies interacted with $\boldsymbol{A}$ in equation 3 reduces the size of the effect on $E L A$ at ages 26 to 30 on women's labor-force participation by around two thirds (extent: 0.013 , s.e. $=0.008$, annual hours: 46.0, s.e. $=23.1$ ) ${ }^{40}$ The inclusion of only education dummies interacted with $\boldsymbol{A}$ reduces the point estimates for the same age group by approximately one third (extent: 0.026, s.e. $=0.009$, annual hours: 56.0, s.e. $=18.7$ ). The inclusion of both occupational and education dummies interacted with $\boldsymbol{A}$ drives the effect of $E L A$ on being in the labor market to zero, and the effect on annual hours worked remains only marginally statistically significant at 43.0 (s.e. $=22.4){ }^{41}$ It seems fair to conclude that net of changes in occupation and education, ELA appears to have had little effect on women's market work. These results reinforce the claim that changing career trajectories, resulting from delay in childbearing, constitute the primary mechanism connecting early access to the pill to increases in labor-force participation.

\section{More Power to the Pill}

Economists have been hesitant to credit fertility control with shaping women’s post-war labor supply. Instead, studies have emphasized real wage growth for women [Smith and Ward 1985, 1989; Goldin 1990], falling discrimination including the elimination of marriage bars [Goldin 1988, 1990], rising demand for labor in the clerical sector [Goldin 1984, Smith and Ward 1985], the growing demand for highly-skilled workers [Black and Juhn 2000, Welch 2000], and the diffusion of labor-saving technologies within the household [Greenwood et al. 2005]. This paper's results do not discount the importance of these factors in reshaping women's employment decisions. On the contrary, oral contraceptives might have mattered very little in the absence of these changes. It was, however, within the social, legal and economic context of the 1960s and 1970s that the pill provided a powerful tool for women wishing to capitalize on the emerging labor market opportunities.

While this analysis can provide only a rough approximation of its importance, oral contraception appears to have had large and permanent effects on young women’s fertility and labor market activity. Using plausibly exogenous changes in laws restricting the age at which young women could consent to medical care, I find that cohorts with earlier legal access to the pill had fewer births before age 21 and worked more for pay during their late

\footnotetext{
${ }^{40}$ These figures are obtained by running the specification in column 4 of Table IV and column 9 of Table V.

${ }^{41}$ The remaining effect on annual hours worked may be due to imprecise proxies for occupation in the CPS.
} 
twenties and early thirties. The estimates are surprisingly strong and quite robust, despite the fact that data limitations - including the inability to observe whether laws were enforced, whether young women could pay for the pill, and whether doctors actually prescribed pills to younger women-tend to attenuate the estimates.

There are other reasons to believe the estimates of the pill's impact are conservative. Reliance on variation in early access to the pill does not allow for the effects of access to the pill at age 21 (or later) to be estimated. Furthermore, within cohort comparisons do not account for the possibility that greater access to the pill had spillover effects across cohorts within states or within cohorts across states. For instance, early access to the pill may have altered norms governing women's labor market roles in addition to its effects on individual women's decisions. In the estimation, however, these effects are captured in the year of birth fixed effects and state-trends. Yet even these conservative estimates suggest that early access to the pill can account for 3 of the 19 percentage point increase (15 percent) in labor-force participation rates and 370 of the 450 increase in annual hours worked (82 percent) among women ages 16 to 30 year olds from 1970 to $1990 .^{42}$

Broadly speaking, this paper advances the hypothesis that greater fertility control contributed to the boom in young women’s market work from 1970 to 1990. More importantly, the findings provoke larger questions about the influence of better birth control on many other outcomes of interest, including family formation, childrearing, education, and wage growth. Further study of the importance of oral contraceptives—as well as other methods of reliable contraception - may advance our understanding of the origins of the second demographic transition and the epochal changes in women's work over the course of the twentieth century.

\section{UNIVERSITY OF MICHIGAN}

\footnotetext{
${ }^{42}$ Using the estimates from the baseline model in equation 3 (including abortion controls), I generate counterfactuals of labor-force participation by assuming that no state had a law that permitted early legal access. That is, I replace ELA with zero and predict the baseline model. This allows me to capture how changing cohort size or year specific effects (like Roe v. Wade or the U.S. business cycle), state trends and the secular increase in cohort participation would have affected women's participation in the absence of liberalization. I then attribute the difference in the simulated and the observed participation rates to early access. As with any counterfactual computation, these numbers should be viewed cautiously.
} 


\section{$\underline{\text { References }}$}

Angrist, Joshua D. and William N. Evans, “Children and Their Parents’ Labor Supply: Evidence from Exogenous Variation in Family Size,” American Economic Review, LXXXVIII (1998), 450-477.

Angrist, Joshua D. and William N. Evans, "Schooling and Labor Market Consequences of the 1970 State Abortion Reforms,” Research in Labor Economics, XVIII (1999), 75-113.

Becker, Gary S. A Treatise on the Family, enlarged edition (Cambridge, MA: Harvard University Press, 1991).

Black, Sandra and Chinhui Juhn, "The Rise in Female Professionals: Are Women Responding to Skill Demand?” American Economic Review, CX (2000), 450-455.

Brandt, Allan M., No Magic Bullet: A Social History of Venereal Disease in the United States Since 1880 (New York, NY: Oxford University Press, 1985).

Brodie, Janet Farrell, Contraception and Abortion in $19^{\text {th }}$ Century America (Ithaca, NY: Cornell University Press, 1994).

Bronars, Steven G. and Jeff Grogger, "The Economic Consequences of Unwed Motherhood: Using Twin Births as a Natural Experiment,” American Economic Review LXXXIV (1994), 1141-1156.

Current Population Surveys, March 1964-2001 [machine readable data files]/conducted by the Bureau of the Census for the Bureau of Labor Statistics (Washington, D.C.: Bureau of the Census [producer and distributor], 1984-2001; Santa Monica, CA: Unicon Research Corporation [producer and distributor of CPS Utilities], 2003).

Department of Health and Economic Welfare (DHEW) Center for Family Planning Program Development (Planned Parenthood-World Population), Family planning, contraception, and voluntary sterilization : an analysis of laws and policies in the United States, each State and jurisdiction (as of September 1971): a report of the National Center for Family Planning Services, Health Services and Mental Health Administration (Rockville, MD: U.S. DHEW, publication no. 74-16001, 1974).

Division of Vital Statistics, Center for Health Statistics, “Table 1-2 First Birth Rates by Age of Mother, According to Race and Hispanic Origin: United States, Specified Years 1940-1955 and Each Year 1960-1994,” in National Statistical Tables on Births (2003).

Garrow, David, Liberty and Sexuality : The Right to Privacy and the Making of Roe v. Wade (New York, NY: Macmillan, 1994).

Goldin, Claudia, “The Historical Evolution of Female Earnings Functions and Occupations,” Explorations in Economic History, XXI (1984), 1-27.

Goldin, Claudia, “Marriage Bars: Discrimination Against Married Women Workers, 1920 to 1950,” National Bureau of Economic Research Working Paper 2747 (1988).

Goldin, Claudia, Understanding the Gender Gap: An Economic History of American Women (New York, NY: Oxford University Press, 1990).

Goldin, Claudia and Lawrence Katz, “The Power of the Pill: Oral Contraceptives and Women’s Career and Marriage Decisions,” Journal of Political Economy, CX (2002), 730-770.

Greenwood, Jeremy, Anath Seshadri and Mehmet Yorukoglu, “Engines of Liberation,” Review of Economic Studies, LXXII (2005), 109-133.

Guldi, Melanie, "Abortion or the Pill—Which Matters More? The Impact of Access on the Birthrates of Young Women,” Mimeo, UC Davis (2005).

Happel, S. J. Hill and S. Low, “An Economic Analysis of the Timing of Childbirth,” Population Studies, XXXVIII (1984), 299-311.

Hirsch, Barry T. and Edward J. Schumacher. "Match Bias in Wage Gap Estimates Due to Earnings Imputation,” 
Journal of Labor Economics 22 (July 2004), 689-722.

Hotz, V. Joseph, Susan McElroy, and Seth Sanders, "The Impact of Teenage Childbearing on the Mothers and the Consequences of those Impacts for Government,” in R. Maynard, ed., Kids Having Kids: Economic Costs and Social Consequences of Teen Pregnancy (Washington, D.C.: The Urban Institute Press, 1997).

Hotz, V.J., Jacob Alex Klerman and Robert J. Willis, “The Economics of Fertility in Developed Countries,” in M.R. Rosezweig and O. Stark, eds., Handbook of Population and Family Economics (Amsterdam: Elsevier, 1997), 275-342.

Jacobsen, Joyce P., James Wishart Pearce III and Joshua L. Rosenbloom, “The Effects of Childbearing on Married Women's Labor Supply and Earnings: Using Twin Births as a Natural Experiment,” The Journal of Human Resources, XXXIV (1999), 449-474

Klepinger, Daniel, Shelly Lundberg, and Robert Plotnick, "How Does Adolescent Fertility Affect Human Capital and Wages of Young Women?” Journal of Human Resources, XXXIV (1999), 421-448.

Levine, Phillip, Douglas Staiger, Thomas J. Kane, David J. Zimmerman, “Roe v. Wade and American Fertility,” American Journal of Public Health, LXXXIX (1999), 199-203.

Marks, Lara V., Sexual Chemistry: A History of the Contraceptive Pill (New Haven, CT: Yale University Press, 2001).

Michael, Robert T. and Robert J. Willis, “Contraception and Fertility: Household Production under

Uncertainty,” in Demographic Behavior of the Household (Cambridge, MA: National Bureau of Economic Research, 1972).

Miller, Amilia, "Effects of Motherhood Timing on Career Path,” manuscript, Stanford University, November 2003.

Mincer, Jacob and Solomon Polachek, "Family Investments in Human Capital: Earnings of Women,” The Journal of Political Economy LXXXII (1974), S76-S108.

National Council of the Churches of Christ in the U.S.A. Churches and Church Membership in the United States: An Enumeration, Series A, No. 3, 1956.

National Archives at College Park, "[Southeast Asia] Combat Area Casualties Current File (CACCF), as of November 1997” (Washington, D.C.: Records of the Office of the Secretary of Defense, Record Group 330, electronic record, 1997).

Paul, Eve, Harriet Pilpel, and Nancy Wechsler, “Pregnancy, Teenagers and the Law, 1974,”'Family Planning Perspectives, VI (1974), 142-147.

Paul, Eve, Harriet Pilpel, and Nancy Wechsler, “Pregnancy, Teenagers and the Law, 1976,” Family Planning Perspectives, VIII (1976), 16-21.

Pilpel, Harriet and Nancy Wechsler, “Birth Control, Teenagers and the Law: A New Look, 1971,” Family Planning Perspectives, III (1971), 37-45.

Ruggles, Steven, Matthew Sobek, et al., Integrated Public Use Microdata Series. (Minneapolis, MN: Historical Census Projects, University of Minnesota, 2004).

Smith, James P. and Michael Ward, “Time Series Growth in the Female Labor Force,” Journal of Labor Economics, III (1985), S59-S90.

Smith, James P. and Michael Ward, "Women in the Labor Market and in the Family,” Journal of Economic Perspectives, III (1989), 9-23.

Tone, Andrea, Devices and Desires: A History of Contraceptives in America, (New York, NY: Hill and Wang, 2001).

U.S. Census Bureau, Statistical Abstract of the United States, (Washington, D.C.: U.S. Dept. of Commerce, 
Economics and Statistics Administration, Bureau of the Census, Data User Services Division, 1967, 1968, 1971, 1981, 1983, 1991, 2001).

Valdiserri, Ron O., “Cum Hastis Sic Clypeatis: The Turbulent History of the Condom,” Bulletin of the New York Academy of Medicine, LIV (1988), 237- 245.

Vere, James P., "Dragon Children: Identifying the Causal Effect of the First Child on Female Labor Supply with the Chinese Lunar Calendar," Economics Working Paper Archive at WUSTL 407003 (October 18, 2004).

Weis, Yoram, "The Determination of Life-Time Earnings: A Survey," in Ashenfelter, O. and R. Layard, eds., Handbook of Labor Economics (Amsterdam: North-Holland, 1986).

Hotz, V. Joseph, Susan McElroy, and Seth Sanders, "The Impact of Teenage Childbearing on the Mothers and the Consequences of those Impacts for Government,” in R. Maynard, ed., Kids Having Kids: Economic Costs and Social Consequences of Teen Pregnancy (Washington, D.C.: The Urban Institute Press, 1997).

Welch, Finis, “Growth in Women's Relative Wages and in Inequality among Men: One Phenomenon or Two?” American Economic Review, XC (2000) 444-449.

Willis, Robert J. “A New Approach to the Economic Theory of Fertility Behavior,” Journal of Political Economy, LXXXI (1973) S14-S64. 
Table II

1960 State-Level Predictors of Liberalization

\begin{tabular}{|c|c|c|c|c|c|c|}
\hline \multicolumn{7}{|c|}{ A. Demographic characteristics } \\
\hline & \multicolumn{3}{|c|}{ Fraction of population } & \multicolumn{3}{|c|}{ Fraction of women in age group } \\
\hline & $\begin{array}{l}\text { living on } \\
\text { farm }\end{array}$ & Black & South & $15-21$ & $22-30$ & $31-45$ \\
\hline Point estimate & -0.804 & -2.10 & -0.673 & 10.6 & 13.9 & 12.4 \\
\hline S.e. & {$[5.077]$} & [3.65] & {$[1.06]$} & {$[7.51]$} & [9.85] & {$[24.0]$} \\
\hline $\mathrm{R}^{2}$ & 0.000 & 0.005 & 0.009 & 0.059 & 0.033 & 0.016 \\
\hline
\end{tabular}

\section{B. Social characteristics}

\begin{tabular}{|c|c|c|c|c|c|c|}
\hline & \multirow{2}{*}{$\begin{array}{c}\text { Mean } \\
\text { years } \\
\text { education } \\
\text { for women }\end{array}$} & \multicolumn{2}{|c|}{ Women born 1920-29 } & \multicolumn{3}{|c|}{ Fraction of the population } \\
\hline & & $\begin{array}{l}\text { Age of } \\
\text { first } \\
\text { marriage }\end{array}$ & $\begin{array}{l}\text { Children } \\
\text { ever born }\end{array}$ & $\begin{array}{c}\text { In } \\
\text { poverty }\end{array}$ & Catholic & $\begin{array}{c}\text { Casualty } \\
\text { rate in } \\
\text { Vietnam }\end{array}$ \\
\hline Point estimate & 0.485 & -0.217 & -18.0 & -2.346 & 5.34 & -1.17 \\
\hline S.e. & {$[0.666]$} & [0.487] & [12.1] & [3.74] & [2.57] & [1.47] \\
\hline $\mathrm{R}^{2}$ & 0.009 & 0.003 & 0.042 & 0.010 & 0.056 & 0.008 \\
\hline
\end{tabular}

\section{Household technology}

Point estimate

S.e.

$\mathrm{R}^{2}$

\section{Labor markets}

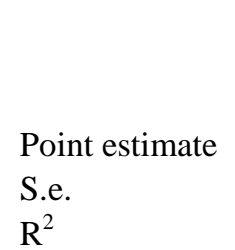

\begin{tabular}{cccccc}
\hline \multicolumn{7}{c}{ Fraction of households with } \\
Radio & Washer & Dryer & Freezer & $\geq 1$ car & $\geq 2$ cars \\
\hline-5.58 & 1.05 & -2.75 & -1.94 & -3.91 & 12.8 \\
{$[8.16]$} & {$[4.09]$} & {$[4.70]$} & {$[3.69]$} & {$[5.89]$} & {$[13.9]$} \\
0.009 & 0.003 & 0.010 & 0.011 & 0.023 & 0.006
\end{tabular}

The dependent variable is the year in each state, in which unmarried women under the age of 21 could legally obtain contraceptives without parental consent, minus 1960, the year the pill was introduced. Regressors are population weighted state aggregates. The point estimates are obtained by regressing the dependent variable on each state characteristic individually. Results from regressions including all the variables in a given panel do not alter the results. All regressions are unweighted. Robust standard errors are reported in brackets. There are 51 observations in each regression with two exceptions. In Panel B, 49 states are included for the regression with fraction Catholic because the 1952 Survey of Churches and Church Membership only included the 48 contiguous U.S. states and the District of Columbia. In Panel C, Alaska is omitted from the fourth regression, "Freezer”, as every household in the Alaska reported 1 or more freezer.

Sources: 1960 PUMS [Ruggles and Sobek 2004]. Data on church membership obtained from the National Council of the Churches of Christ in the U.S.A. [1956]. Data on Vietnam casualties obtained from the National Archives [1997]. 
Table III

The effect of early legal access to the pill on fertility

\begin{tabular}{|c|c|c|c|c|c|c|}
\hline \multirow[t]{2}{*}{ Dependent variable } & \multicolumn{3}{|c|}{ 1=First birth before age $22^{a}$} & \multirow{2}{*}{$\begin{array}{c}1=\text { Before } 19^{b} \\
\text { (4) }\end{array}$} & \multirow{2}{*}{$\begin{array}{c}1=\text { Before } 36^{c} \\
\text { (5) }\end{array}$} & \multirow{2}{*}{$\begin{array}{l}\text { Children ever } \\
\text { born }{ }^{\mathrm{d}} \\
(6)\end{array}$} \\
\hline & (1) & (2) & (3) & & & \\
\hline Mean dept. variable & & 0.497 & & 0.201 & 0.973 & 2.38 \\
\hline ELA to pill & -0.071 & -0.076 & -0.093 & -0.011 & -0.001 & -0.062 \\
\hline & [0.039] & [0.039] & [0.043] & [0.037] & [0.031] & {$[0.086]$} \\
\hline Early legal access to abortion & & & -0.074 & -0.086 & -0.006 & 0.242 \\
\hline & & & [0.057] & [0.045] & {$[0.006]$} & [0.120] \\
\hline ELA to pill \& abortion & & & 0.057 & 0.002 & 0.005 & -0.186 \\
\hline & & & {$[0.082]$} & {$[0.065]$} & {$[0.008]$} & [0.114] \\
\hline Fixed effects & $\mathrm{S}, \mathrm{C}^{\mathrm{e}}$ & $\mathrm{S}, \mathrm{C}, \mathrm{SxC}^{\mathrm{e}, \mathrm{f}}$ & $\mathrm{S}, \mathrm{C}, \mathrm{SxC} \mathrm{C}^{\mathrm{e}, \mathrm{f}}$ & $\mathrm{S}, \mathrm{C}, \mathrm{SxC}^{\mathrm{e}, \mathrm{f}}$ & $\mathrm{S}, \mathrm{C}, \mathrm{SxC}^{\mathrm{e}, \mathrm{f}}$ & $\mathrm{S}, \mathrm{C}, \mathrm{SxC} \mathrm{C}^{\mathrm{e}, \mathrm{f}}$ \\
\hline Observations & 91791 & 91791 & 91791 & 91791 & 91791 & 91791 \\
\hline Log-likelihood & -62118 & -61885 & -61866 & -43968 & -9892 & -145419 \\
\hline
\end{tabular}

Synthetic birth cohorts are computed by using either the reported year of birth or, when this is value is missing, subtracting the reported age in years from the year of the survey. Probits are used for the estimation for columns 1 through 5 and a least squares regression in column 7 . The reported numbers are marginal effects evaluated at the mean. Robust standard errors are reported in brackets and are corrected for clustering on state of residence and year of birth cells. All computations are weighted. ${ }^{a}$ The dependent variable is equal to one for individuals that had a first birth before age 22 conditional upon giving birth. ${ }^{\mathrm{b}}$ The dependent variable is equal to one for individuals that had a first birth before age 19 conditional upon giving birth. ${ }^{\mathrm{c}}$ The dependent variable is equal to one for individuals that had a first birth before age 36 conditional upon giving birth. ${ }^{\mathrm{d}}$ The dependent variable the reported number of children ever born to women with any children. ${ }^{\mathrm{e}} \mathrm{S}$ and $\mathrm{C}$ denote sets of fixed effects for state of residence and year of birth. ${ }^{\mathrm{f}} \mathrm{SxC}$ is a set of dummy variables for state interacted with a linear trend in year of birth. The results for columns 4,5 and 6 without abortion controls are reported in the text.

Sample: Women ages 36 to 44 who were born between 1935 and 1960.

Source: 1977-1995 June CPS (not including the years 1978, 1984, 1989, 1991, 1993, and 1994 when the survey or information on first birth was not collected). 
Table IV

The effect of early access to contraception on labor market participation

\begin{tabular}{|c|c|c|c|c|c|c|}
\hline \multirow[t]{3}{*}{ Dependent variable } & \multirow{3}{*}{$\begin{array}{c}\text { Mean dept. } \\
\text { variable }^{\mathrm{a}}\end{array}$} & \multicolumn{4}{|c|}{ 1=In the labor force } & \multirow{3}{*}{$\begin{array}{c}\text { June } C P S \\
(5)\end{array}$} \\
\hline & & \multicolumn{4}{|c|}{ March $C P S$} & \\
\hline & & $(1)$ & $(2)$ & (3) & (4) & \\
\hline ELA to pill $x$ 21-25 & 0.605 & $\begin{array}{c}0.003 \\
{[0.006]}\end{array}$ & $\begin{array}{c}0.005 \\
{[0.006]}\end{array}$ & $\begin{array}{c}-0.003 \\
{[0.008]}\end{array}$ & $\begin{array}{c}0.009 \\
{[0.009]}\end{array}$ & $\begin{array}{c}-0.048 \\
{[0.059]}\end{array}$ \\
\hline ELA to pill x 26-30 & 0.580 & $\begin{array}{c}0.039 \\
{[0.007]}\end{array}$ & $\begin{array}{c}0.042 \\
{[0.006]}\end{array}$ & $\begin{array}{c}0.040 \\
{[0.009]}\end{array}$ & $\begin{array}{c}0.028 \\
{[0.010]}\end{array}$ & $\begin{array}{c}0.005 \\
{[0.022]}\end{array}$ \\
\hline ELA to pill x 31-35 & 0.640 & $\begin{array}{c}0.016 \\
{[0.006]}\end{array}$ & $\begin{array}{c}0.019 \\
{[0.006]}\end{array}$ & $\begin{array}{c}0.022 \\
{[0.009]}\end{array}$ & $\begin{array}{c}0.019 \\
{[0.010]}\end{array}$ & $\begin{array}{c}0.004 \\
{[0.021]}\end{array}$ \\
\hline ELA to pill x 36-40 & 0.711 & $\begin{array}{c}-0.002 \\
{[0.007]}\end{array}$ & $\begin{array}{c}0.002 \\
{[0.006]}\end{array}$ & $\begin{array}{c}0.004 \\
{[0.010]}\end{array}$ & $\begin{array}{c}0.007 \\
{[0.008]}\end{array}$ & $\begin{array}{c}0.001 \\
{[0.023]}\end{array}$ \\
\hline ELA to pill x 41-44 & 0.752 & $\begin{array}{c}-0.006 \\
{[0.008]}\end{array}$ & $\begin{array}{c}-0.003 \\
{[0.008]}\end{array}$ & $\begin{array}{c}-0.007 \\
{[0.012]}\end{array}$ & $\begin{array}{c}-0.007 \\
{[0.008]}\end{array}$ & $\begin{array}{c}0.091 \\
{[0.042]}\end{array}$ \\
\hline Fixed effects & & $\mathrm{R}, \mathrm{Y}, \mathrm{C}^{\mathrm{b}}$ & $\begin{array}{c}\text { R,Y,C, } \\
\text { RxYear }^{c}\end{array}$ & $\begin{array}{c}\text { R,Y,C, } \\
\text { RxYear }^{c}\end{array}$ & $\begin{array}{c}\text { R,Y,C, } \\
\text { RxYear }^{c}\end{array}$ & $\begin{array}{c}\text { S, C, } \\
\text { SxYear d }\end{array}$ \\
\hline Age of majority states & & & & $\mathrm{X}$ & & \\
\hline Abortion controls ${ }^{\mathrm{e}}$ & & & & & $\mathrm{X}$ & $\mathrm{X}$ \\
\hline First birth before $22^{\mathrm{f}}$ & & & & & & Yes \\
\hline Observations & & 733419 & 733419 & 245943 & 733419 & 103972 \\
\hline Log likelihood & & -454635 & -454359 & -150263 & -454341 & -59671 \\
\hline
\end{tabular}

Synthetic birth cohorts are computed by subtracting the reported age from the year of the survey. The dependent variable is equal to 1 if a woman worked in the

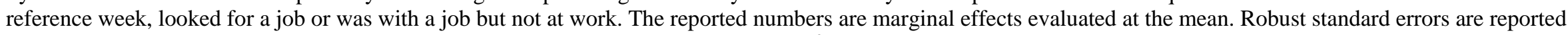

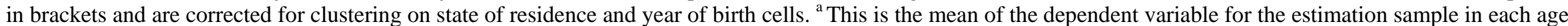
group in the March $C P S .{ }^{\mathrm{b}} \mathrm{R}, \mathrm{Y}$ and $\mathrm{C}$ denote sets of fixed effects for $C P S$ region, year of observation and year of birth. ${ }^{\mathrm{c}} \mathrm{RxY}$ ear is a set of dummy variables for $C P S$ region interacted with a linear time trend. ${ }^{\mathrm{d}} \mathrm{S}$ denotes a set of dummy variables for state of residence. SxYear denotes the interaction of state dummies with linear time trends. ${ }^{\text {e }}$ Abortion controls are generated in the same manner as in Table III. Early access to abortion is interacted with dummies for the age categories presented in the analysis and triple interaction terms, ELA x early access to abortion x age dummies are included as well. ${ }^{\mathrm{f}}$ A sample of women is drawn from the June $C P S$ who reported a first birth before age 22 .

Sample: Women ages 16 to 45 not in the military or inmates born from 1935 to 1960.

Source: 1964-2001 March CPS, 1977-1995 June CPS. 
Table V

The effect of early access to contraception on intensity of market work

\begin{tabular}{|c|c|c|c|c|c|c|c|c|c|}
\hline \multirow[t]{2}{*}{ Dependent variable } & \multicolumn{3}{|c|}{ "Hours worked last week ${ }^{a}$} & \multicolumn{3}{|c|}{ Weeks worked last year ${ }^{\mathrm{b}}$} & \multicolumn{3}{|c|}{$\begin{array}{c}\text { Implied annual hours }^{\mathrm{c}} \\
\end{array}$} \\
\hline & (1) & (2) & (3) & (4) & (5) & (6) & (7) & (8) & (9) \\
\hline ELA x 21-25 & $\begin{array}{c}0.206 \\
{[0.229]}\end{array}$ & $\begin{array}{l}-0.442 \\
{[0.389]}\end{array}$ & $\begin{array}{c}0.535 \\
{[0.361]}\end{array}$ & $\begin{array}{l}-0.257 \\
{[0.257]}\end{array}$ & $\begin{array}{l}-0.625 \\
{[0.427]}\end{array}$ & $\begin{array}{c}0.044 \\
{[0.396]}\end{array}$ & $\begin{array}{c}7.81 \\
{[10.4]}\end{array}$ & $\begin{array}{l}-19.3 \\
{[17.5]}\end{array}$ & $\begin{array}{c}28.3 \\
{[17.9]}\end{array}$ \\
\hline ELA x 26-30 & $\begin{array}{c}2.34 \\
{[0.285]}\end{array}$ & $\begin{array}{c}1.68 \\
{[0.497]}\end{array}$ & $\begin{array}{c}1.5 \\
{[0.411]}\end{array}$ & $\begin{array}{c}2.34 \\
{[0.320]}\end{array}$ & $\begin{array}{c}1.66 \\
{[0.525]}\end{array}$ & $\begin{array}{c}1.43 \\
{[0.481]}\end{array}$ & $\begin{array}{c}107 \\
{[13.4]}\end{array}$ & $\begin{array}{c}73.5 \\
{[23.8]}\end{array}$ & $\begin{array}{c}68.5 \\
{[20.8]}\end{array}$ \\
\hline ELA x 31-35 & $\begin{array}{c}1.51 \\
{[0.270]}\end{array}$ & $\begin{array}{c}1.63 \\
{[0.441]}\end{array}$ & $\begin{array}{c}0.975 \\
{[0.425]}\end{array}$ & $\begin{array}{c}1.73 \\
{[0.308]}\end{array}$ & $\begin{array}{c}1.54 \\
{[0.494]}\end{array}$ & $\begin{array}{c}1.33 \\
{[0.493]}\end{array}$ & $\begin{array}{c}71.2 \\
{[13.4]}\end{array}$ & $\begin{array}{c}72.1 \\
{[22.6]}\end{array}$ & $\begin{array}{c}50.3 \\
{[21.3]}\end{array}$ \\
\hline ELA x 36-40 & $\begin{array}{c}0.555 \\
{[0.268]}\end{array}$ & $\begin{array}{c}0.905 \\
{[0.457]}\end{array}$ & $\begin{array}{c}0.422 \\
{[0.334]}\end{array}$ & $\begin{array}{c}0.544 \\
{[0.309]}\end{array}$ & $\begin{array}{c}1.01 \\
{[0.507]}\end{array}$ & $\begin{array}{c}0.233 \\
{[0.412]}\end{array}$ & $\begin{array}{c}29.1 \\
{[14.1]}\end{array}$ & $\begin{array}{c}47.0 \\
{[25.0]}\end{array}$ & $\begin{array}{c}18.2 \\
{[17.3]}\end{array}$ \\
\hline ELA x 41-44 & $\begin{array}{c}0.464 \\
{[0.298]}\end{array}$ & $\begin{array}{c}0.871 \\
{[0.497]}\end{array}$ & $\begin{array}{c}0.512 \\
{[0.352]}\end{array}$ & $\begin{array}{c}0.316 \\
{[0.358]}\end{array}$ & $\begin{array}{c}0.332 \\
{[0.614]}\end{array}$ & $\begin{array}{c}0.203 \\
{[0.371]}\end{array}$ & $\begin{array}{c}29.4 \\
{[15.6]}\end{array}$ & $\begin{array}{c}46.9 \\
{[26.8]}\end{array}$ & $\begin{array}{c}31.2 \\
{[18.3]}\end{array}$ \\
\hline Fixed effects & $\begin{array}{c}\text { R,Y,C, } \\
\text { RxYear }^{\mathrm{d}}\end{array}$ & $\begin{array}{l}\text { R,Y,C, } \\
\text { RxYear }^{d}\end{array}$ & $\begin{array}{c}\text { R,Y,C, } \\
\text { RxYear }^{d}\end{array}$ & $\begin{array}{c}\text { R,Y,C, } \\
\text { RxYear }^{\mathrm{d}}\end{array}$ & $\begin{array}{l}\text { R,Y,C, } \\
\text { RxYear }^{d}\end{array}$ & $\begin{array}{c}\text { R,Y,C, } \\
\text { RxYear }^{\mathrm{d}}\end{array}$ & $\begin{array}{c}\text { R,Y,C, } \\
\text { RxYear }^{\mathrm{d}}\end{array}$ & $\begin{array}{c}\text { R,Y,C, } \\
\text { RxYear }^{d}\end{array}$ & $\begin{array}{l}\text { R,Y,C, } \\
\text { RxYear }^{\mathrm{d}}\end{array}$ \\
\hline $\begin{array}{l}\text { Age of majority } \\
\text { states }\end{array}$ & & $\mathrm{X}$ & & & $\mathrm{X}$ & & & $\mathrm{X}$ & \\
\hline Abortion controls & & & $\mathrm{X}$ & & & $\mathrm{X}$ & & & $\mathrm{X}$ \\
\hline Observations & 730384 & 244661 & 730384 & 733419 & 245943 & 733419 & 730384 & 244661 & 730384 \\
\hline Adjusted R-squared & 0.066 & 0.056 & 0.066 & 0.073 & 0.058 & 0.073 & 0.088 & 0.079 & 0.088 \\
\hline
\end{tabular}

Synthetic birth cohorts are computed by subtracting the reported age from the year of the survey. All computations are weighted. Robust standard errors are reported in

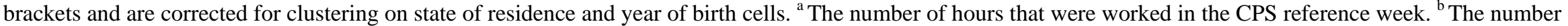
of weeks that were worked in the previous calendar year. ${ }^{\mathrm{c}}$ The product of ${ }^{\mathrm{a}}$ and ${ }^{\mathrm{b}} .{ }^{\mathrm{d}} \mathrm{R}, \mathrm{Y}$ and $\mathrm{C}$ denote sets of fixed effects for $C P S$ region, year of observation and year of birth. RxYear denotes a set of dummy variables for $C P S$ region interacted with a linear time trend.

Sample: Women ages 16 to 45 not in the military or inmates born 1935 to 1960.

Source: 1964-2001 March CPS. 


\section{Figure I}

Live first birth rates by age of mother, 1940-1995

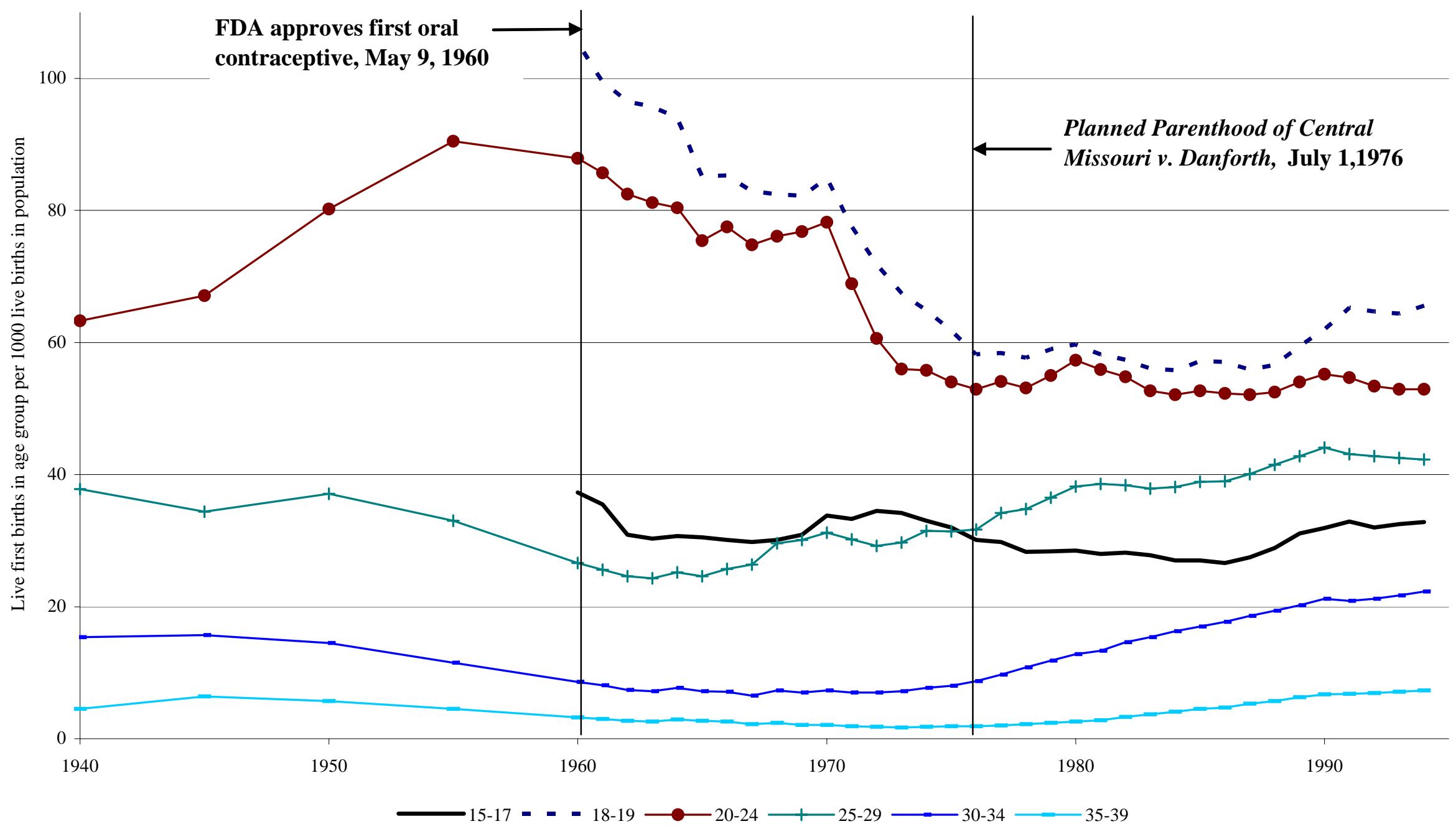

First birth rates are computed as the number of live first births per 1000 women in the appropriate age group. 
Source: Division of Vital Statistics, National Center for Health Statistics, Statistical Tables on Births, Table 1 and 2: First birth rates by Age of Mother, According to Race and Hispanic Origin: United States, Specified Years 1940-1955 and Each Year 1960-1994 (2003). 


\section{Figure II}

The distribution of age at first birth, by cohort

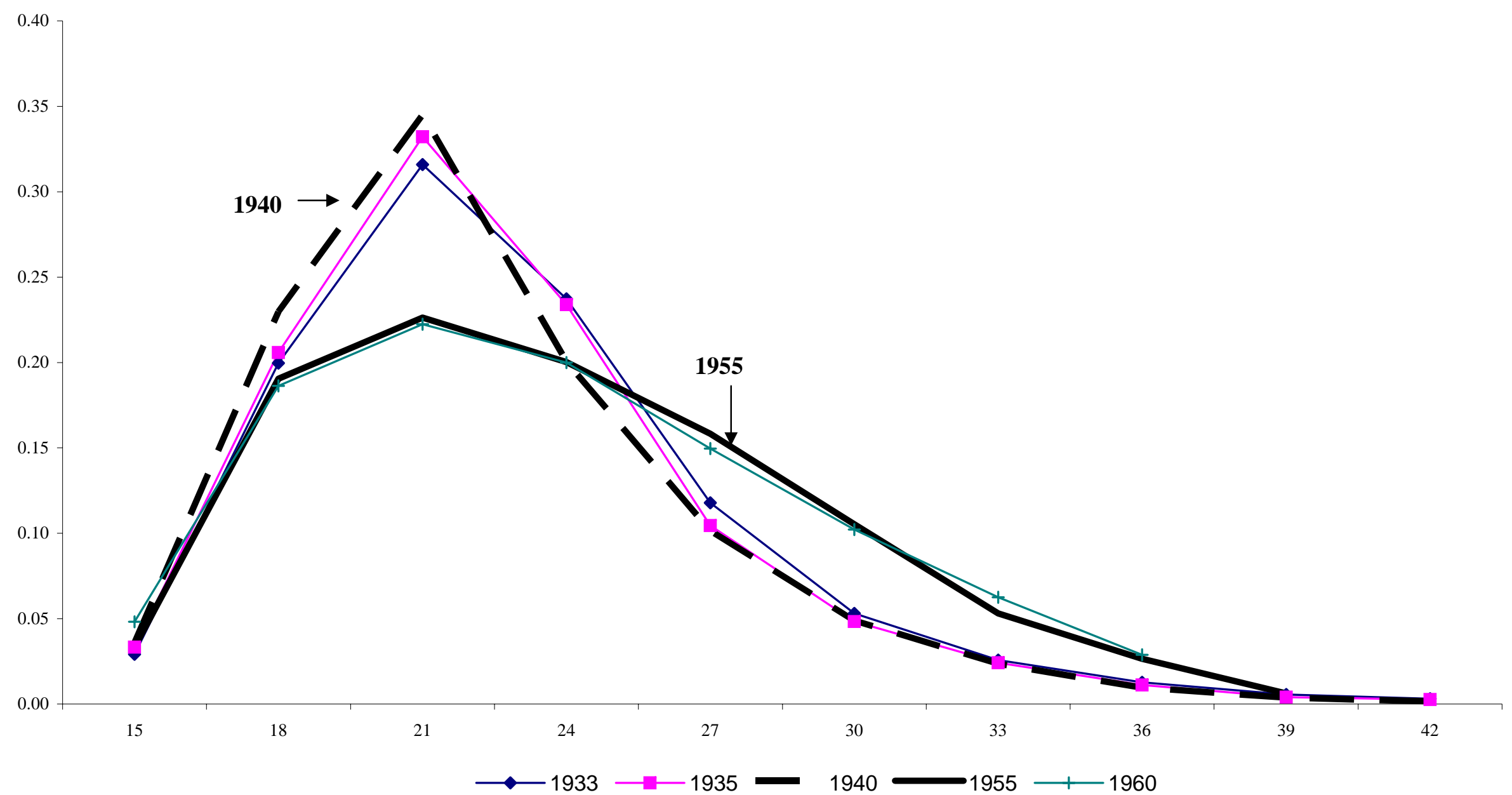

The figure plots the fraction of women (vertical axis) with a first birth at a particular age (horizontal axis). Synthetic birth cohorts are generated by computing the year of birth (reported age from the year of the survey). Sample includes women who were ages 35 to 44 at the time of the survey who had ever given birth.

Source: June CPS 1977-1995. 
Figure III

Age-specific labor-force participation rates, by cohort and age 1900-1970

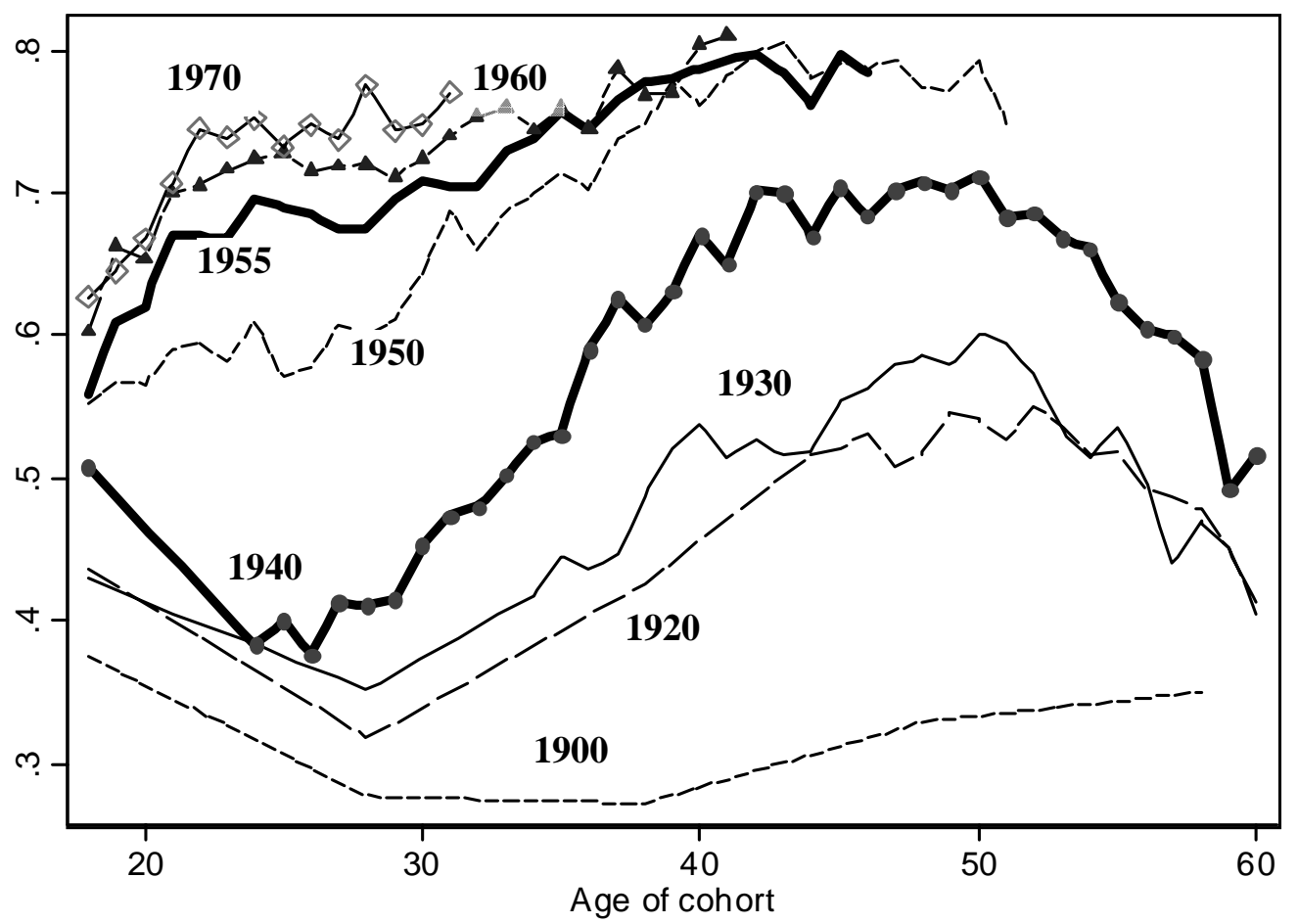

Pre-1964 data are averaged over cohorts as in Smith and Ward (1985, Table 1). For instance, the participation rate for women ages 14 to 19 in 1950 is plotted in this figure as the cohort of 1930 at those ages. Data after 1963 represent participation rates for a single year of birth cohort at the reported age. Synthetic birth cohorts are computed by subtracting the reported age from the year of the survey. Bold lines depict the 1940 and 1955 cohorts. The March sample includes all women not in military or inmates ages 16 to 60 .

Source: 1964-2001 March CPS; for years before 1964, data is from Smith and Ward (1985, Table 1). 